
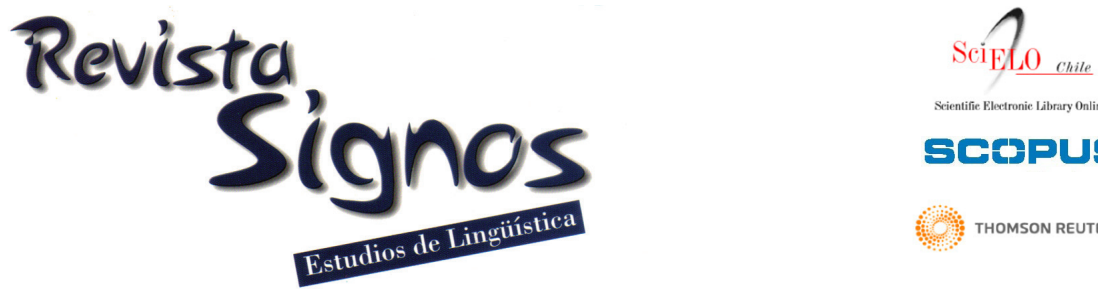

\title{
Representación socio-discursiva de los actores implicados en el ataque a una joven ecuatoriana en un tren de cercanías de Barcelona: Estudio de caso
}

\section{Socio-discursive representation of the actors involved in the attack against a young Ecuadorian girl on a suburban train in Barcelona: A case study}

\author{
Francisco Rodríguez \\ frodriguez@ual.es \\ Universidad de Almería \\ España
}

\author{
Julia Williams \\ jtwilliams.camus@gmail.com \\ Universitat Pompeu Fabra \\ España
}

Recibido: 22-VII-20I0 / Aceptado: 20-IV-20II

\begin{abstract}
Resumen: Este trabajo presta atención a la representación socio-discursiva de los actores implicados en una agresión de tipo racial en un tren de cercanías de Barcelona. Los materiales analizados incluyen dos subcorpus de prensa ecuatoriana y española. El análisis, de carácter cuantitativo y cualitativo, se basa en la descripción de los actores que protagonizaron la escena (agresor, víctima y testigo). De acuerdo con los resultados, la prensa de ambos países reconstruyó los hechos mediante un procedimiento socio-discursivo análogo que consistió en la inclinación hacia los miembros de nacionalidades afines con cada grupo de medios escritos. Esto es, la atenuación de la responsabilidad del agresor en los medios españoles y el énfasis puesto en la indefensión de la víctima en los textos ecuatorianos a juzgar por las denominaciones, caracterizaciones y acciones que les fueron atribuidas y las cuales constituyen las categorías básicas de este análisis.
\end{abstract}

Palabras Clave: Prensa, estudios críticos del discurso, mujer, inmigración. 


\begin{abstract}
This study is an account of the socio-discursive representation of the actors involved in a racial aggression which took place on a suburban train in Barcelona. The data includes two subcorpora from the Ecuadorian and Spanish press. The quantitative and qualitative analysis is based on the description of the actors present in the scene (aggressor, victim and witness). The results reveal that the press in both countries reconstructed the events through an analogous socio-discursive procedure which involved favouring the members of nationalities akin to each group of the written media; that is, attenuating the responsibility of the aggressor in the Spanish media and stressing the defenceless condition of the victim in the Ecuadorian texts, as shown by the denominations, characterisation and actions attributed to each side, which constitute the basic categories for this analysis.
\end{abstract}

Key Words: Press, critical discourse studies, woman, immigration.

\section{INTRODUCCIÓN}

En los últimos años, han ido en aumento los estudios críticos sobre la representación de los inmigrantes y de las mujeres en la prensa. Sin embargo, no parece suficiente la literatura existente que da cuenta de las representaciones socio-discursivas de inmigrantes y mujeres conjuntamente.

Desde diversos campos de estudio, se ha insistido en el poder que tienen los medios de comunicación en la producción de representaciones culturales y en la conformación de identidades. Los trabajos que han indagado en la representación de las mujeres en los medios ofrecen resultados previsibles y señalan que el mismo fenómeno se repite en diversos países, a saber: la escasa presencia de las mujeres en los discursos periodísticos, la existencia de textos que refuerzan los roles que se les asignan tradicionalmente y la carencia de modelos alternativos (Comas d'Argemir, 2008).

En primer lugar, partimos de la base de que estos sistemas de información poseen una capacidad potencialmente persuasiva aunque con efectos limitados, ya que cualquier contenido difundido puede ser interpretado de modos muy variados. En segundo lugar, nos interesa plantear un estudio crítico en el que tenga cabida el tratamiento conjunto de las categorías 'mujer' e 'inmigrante' en la prensa escrita; aspecto que algunos autores han calificado como la "crónica de una ausencia" (Aierbe, 2008).

Con este propósito, hemos escogido, por su relevancia y actualidad, un conocido incidente racial que tuvo lugar en un tren de cercanías de Barcelona. Las grabaciones recogidas por las cámaras de seguridad, que semanas más tarde se retransmitieron y difundieron en medios de comunicación nacionales y extranjeros, ofrecen una visión clara del ataque en el que se identifica a tres personas: el agresor, la víctima y un testigo. El altercado, no exento de controversias, tuvo gran repercusión mediática y reabrió el inagotable debate sobre el proceso de integración de los migrantes en sociedades modernas y desarrolladas como la española.

A partir de los textos periodísticos (noticias y artículos de opinión) aparecidos dos semanas después en la prensa española y ecuatoriana, nos ocuparemos de la descripción de los actores presentes en la escena. Para ello, nos centraremos en las representaciones que se desprenden de las denominaciones y caracterizaciones que recibieron los actores implicados, así como de las acciones que les fueron atribuidas.

Algunas cuestiones de partida que nos planteamos al abordar las representaciones socio-discursivas que se derivan de la descripción de los tres actores son: ¿De qué forma es definido cada uno de los actores en la prensa española y en la prensa ecuatoriana? ¿Existen diferencias significativas entre las representaciones de dichos actores en los distintos países? ¿Se mitigan las responsabilidades del agresor en el endogrupo? ¿Se intensifican en el exogrupo? ¿Cómo se califica la agresión en el endogrupo y cómo en el exogrupo? ¿Cómo se desarrollan los procesos argumentativos en la prensa de ambos países?

\section{Claves contextuales}

La agresión del 7 de octubre de 2007 apareció en los medios de comunicación quince días después de que se produjera, debido a la publicación de un vídeo de seguridad donde se podía apreciar claramente el ataque en la línea de tren que va desde Plaza de España a Martorell (en Barcelona), poco antes de llegar a la estación de Colonia Güell, donde el agresor se apeó. La escena tuvo lugar sobre las 23.45 horas y estuvo protagonizada por tres sujetos: 
el agresor, Sergi Xavier Martí Martínez, vecino de Santa Coloma de Cervelló (Barcelona) de veintiún años, la agredida ecuatoriana de dieciséis años y un testigo argentino de veinticuatro años.

La prensa comenta cómo el agresor entra en el transporte manteniendo una conversación telefónica de tono racista. El individuo, tras percatarse de que solo había dos pasajeros más, la víctima y el testigo, se aproxima a la chica de origen ecuatoriano y sin dejar de hablar por el teléfono móvil, acerca su mejilla a la de esta y comienza a insultarla, amenazándola e instándola a regresar a su país. Seguidamente, en el documento visual apreciamos cómo el agresor la golpea, mientras la joven se cubre la cara y este alcanza a pellizcarle el pecho izquierdo. Inmediatamente después, el individuo se aleja un poco, pero cuando parece marcharse, se coloca detrás de la chica y le da una patada en la cara, rematando su intervención con un puñetazo en el costado de la menor. Finalmente, el agresor se dirige a las compuertas del vagón donde se apea. En el vídeo también observamos cómo la joven se levanta y se marcha. El testigo contempla la agresión en todo momento. Tras los ataques, la chica llamó al teléfono de emergencias 112 en la estación de Sant Vicenç dels Horts, donde fue atendida por miembros de la Guardia Civil, quienes la encontraron en estado de choque. En el momento, la menor no quiso recibir asistencia sanitaria ni tampoco denunciar la agresión. Se comentó en la prensa que la joven tenía fobia a salir de casa durante los días posteriores al ataque.

La policía abrió una investigación y solicitó las imágenes que quedaron registradas por las cámaras de los Ferrocarriles de la Generalitat de Cataluña. Tras ser detenido por la Guardia Civil, el agresor pasó a disposición judicial y fue puesto en libertad tras imputarle un delito de lesiones con agravante de racismo. Una vez se tomó declaración a la menor, al agresor y al testigo, el juez obligó a Sergi Xavier a comparecer ante la Policía Local de Santa Coloma de Cervelló dos veces al día, una entre las 10 y las II horas y otra entre las 18 y 19 horas. Asimismo, se le prohibió acercarse a la chica a una distancia menor de mil metros, mantener cualquier tipo de comunicación telefónica o electrónica con ella y salir de su localidad sin previa autorización judicial. En caso de que incumpliera la orden, podría ingresar en prisión.

En Ecuador, la agresión causó gran conmoción. El presidente del país, Rafael Correa, pidió a la ministra de Asuntos Exteriores, María Fernanda Espinosa Garcés, y al embajador de Ecuador en España, Nicolás José Issa Obando, que se desplazaran hasta Barcelona para visitar a la víctima. Además, el Gobierno ecuatoriano contrató los servicios de un despacho de abogados para que representaran a la chica.

Organizaciones no gubernamentales, como SOS Racismo, hicieron un comunicado público donde condenaron los actos racistas. También tuvieron lugar manifestaciones en Ecuador y en España en protesta contra el ataque.

Según la información aparecida el 18 de marzo de 2009 en el diario español El País, el juzgado de lo penal número 16 de Barcelona condenó al agresor a ocho meses de prisión por un delito contra la integridad moral, para el que la Fiscalía pedía tres años de cárcel. Además, la sentencia impuso al acusado una multa de trescientos sesenta euros por una falta de maltrato y obligó a indemnizar a la víctima con una cantidad de seis mil euros por los daños morales que le causó la agresión en la que, según el juez, "hubo una intención directa de humillarla por su condición de mujer e inmigrante". La sentencia recoge que como consecuencia del visionado del vídeo y debido en parte a la reacción de su entorno socio-familiar, así como por la repercusión mediática de los hechos, se inició en la perjudicada "un proceso de victimización secundaria”.

\section{Reflexión teórico-metodológica}

Según KhrosraviNik (2010), dentro de los Estudios Críticos del Discurso (ECD) las investigaciones orientadas a dar cuenta de las representaciones sociales constituyen la mayor parte de los trabajos realizados desde esta aproximación crítica (ver van Dijk (2009) para una discusión terminológica) y se centran en dos niveles principales:

"un nivel descriptivo en el que se analizan los textos y se da cuenta de las características lingüísticas de los mismos, y un nivel explicativo donde los resultados del primero se contextualizan y explican haciendo uso de teorías lingüísticas y sociales. Las elecciones en la metodología del análisis lingüístico y de las teorías socio-políticas explicativas dependen de varios factores: las preguntas de investigación, las posibilidades de análisis que ofrecen los datos, el diseño de 
la investigación y el contexto socio-politico específico que se investiga" (KhrosraviNik, 20l0: 55 , traducción propia).

A continuación, expondremos las teorías sociales sobre las que se apoya nuestro estudio y la metodología que empleamos para el análisis de las representaciones socio-discursivas de los actores presentes en la agresión del tren de cercanías de Barcelona.

\section{I. La construcción social de la realidad}

En palabras de Lario (2008), desde que se publicara 'La construcción social de la realidad', la investigación sobre comunicación de masas ha considerado a los medios como el principal elemento que interviene en la configuración del contexto social:

"Las realidades sociales son realidades pensadas y habladas. (...) Las ideas, los sistemas de valores, las visiones del mundo, las representaciones sociales, el pensamiento social ordinario y su puesta en circulación por medio de las interacciones, a través de la conversación y la comunicación cotidianas; ocupan un lugar preponderante en la construcción, la deconstrucción y la reconstrucción incesantes de lo social" (Windisch, 1990: 25, traducción propia).

Por otro lado, siguiendo a Comas d'Argemir (2008), los medios de comunicación nos informan de mundos que no conocemos directamente y es de este modo como influyen en nuestra comprensión del entorno social y en nuestras actitudes; esto es, nos proporcionan una traducción particular de las percepciones acerca de la sociedad y condicionan nuestras referencias compartidas sobre ella.

Según nuestro planteamiento, el signo construye sentido y cobra sentido en un texto que, a su vez, está inscrito dentro de un determinado contexto; es decir, mediante un proceso de reproducción discursiva. En este caso, concebimos la realidad social como aquello a lo que el ser humano nombra, describe, caracteriza, explica y atribuye sentido en el contexto en el cual se sitúa. En suma, los individuos son quienes, particularmente, dan forma a esa realidad social desprovista, en principio, de sentidos. Por lo tanto, el discurso elabora y reelabora constantemente las percepciones sobre el contexto en el que se genera. Esas elaboraciones y reelaboraciones de una realidad social concreta pueden denominarse 'representaciones sociales' (este concepto tiene un amplio recorrido en el campo de la psicología social y ha recibido diversos enfoques teóricos en investigaciones clásicas como las de Farr \& Moscovici, 1984; Jodelet, 1986, 1989; Banchs, I988; Hall, I997).

El panorama de los estudios sobre las representaciones sociales ha mostrado prolíficos resultados en la última década. Este ha sido el caso de las investigaciones que se han preocupado por las actitudes que intervienen en la construcción social de determinados colectivos en riesgo de exclusión por cuestiones de género (Álvaro \& Fernández, 2006; Moral \& Ortega, 2008) y de procedencia geográfica (Belarbi, 2004; Gil de Montes, Elejabarrieta \& Valencia, 2004; Montero, 2006).

Desde nuestro punto de vista, tras las actitudes $y$, más específicamente, tras el comportamiento social de los individuos subyacen 'estereotipos','prejuicios', 'opiniones', 'creencias', 'valores' y 'normas' que se agrupan y reconocen a través de sistemas cognitivos. Siguiendo las ideas de Abric (1994), el estudio de las representaciones sociales permite entender la dinámica de las relaciones interpersonales y aclarar ciertas condiciones que rigen el entramado de las prácticas sociales. En otras palabras, concebimos que las representaciones, los discursos y las prácticas se generan mutuamente.

La adscripción de las personas a diferentes grupos sociales incide fuertemente en la construcción del contexto social y da lugar a visiones o referencias compartidas del mundo e interpretaciones parecidas de los acontecimientos. Esto presupone un sustrato compartido de ideas $y$, en consecuencia, procesos de intercambio comunicativo situados en un marco discursivo de referencia en el que se elaboran representaciones sociales.

Un aspecto delicado $y$, sin embargo, prioritario en el estudio de las representaciones sociales consiste en establecer el grado de generalización, anclaje, recurrencia o profundidad en que se hallan arraigadas algunas creencias. A partir del análisis crítico de los procesos de construcción textual y discursiva, es posible examinar cómo se explicitan ciertas creencias en diversos dominios sociales (la prensa es uno de ellos). 


\subsection{Metodología}

Como bien apunta KhosraviNik (2010), desde los ECD se han propuesto distintas metodologías y categorías de análisis para dar cuenta de las representaciones sociales, a pesar de que muchas de ellas estén orientadas a la descripción de objetivos similares.

Asimismo, el carácter ecléctico y multidisciplinar de los ECD permite al investigador seleccionar las teorías y las categorías de estudio más relevantes para el objeto de la investigación (van Dijk, 2000). Esta libertad puede ser, en ocasiones, problemática a la hora de diseñar el aparato metodológico.

El planteamiento metodológico de esta investigación se nutre principalmente de las aportaciones de Ribas (I998, 200I, 2007, 2008) y KhosraviNik (20I0) para el estudio crítico-discursivo de las representaciones sociales. Ambos autores proponen métodos de análisis que, aunque diferentes, destacan por ser coherentes y sistemáticos. Tomando sus modelos como referentes claves en este trabajo, hemos diseñado una metodología acorde con los datos que manejamos y destinada a resolver nuestros interrogantes de partida.

La metodología de Ribas (2008) se basa en los componentes temáticos (marcos), léxicos (denominaciones y designaciones), sintácticos (acciones) y retóricos (coherencia del texto), para analizar cómo se 'construye' y 'reproduce' la representación social de la inmigración en el discurso parlamentario. Para la autora:

"analizar el discurso público es percatarse de que los sujetos y las acciones sociales no son más que 'representaciones' construidas y reconstruidas sobre todo a través de los discursos" (Ribas, 1998: 219).

Por su parte, KhosraviNik (20I0) considera un marco analítico de tres niveles (actores, acciones y argumentación) articulados por dos preguntas ('¿qué?' y ‘cómo?') para el análisis textual. De esta manera, se puede dar cuenta de aquello que (no) aparece en los textos, así como examinar la forma en la que las distintas estrategias lingüísticas influyen en la 'perspectivización' del discurso. De acuerdo con el autor:

"La perspectivización [...] es un aspecto global de translación desde la ideología hasta el discurso e incluye todos aquellos procesos discursivos (micro, p. ej., a nivel oracional, o macro, p. ej., a nivel argumentativo) que se acercan $o$ apuntan hacia una ideología social en la realización lingüística. De este modo, la perspectivización incide en todos los niveles de la representación discursiva y por ende, es relevante en todos los niveles de análisis" (KhosraviNik, 20I0: 70, traducción propia).

Situándonos en el marco que sugieren estos autores, en nuestro análisis hemos prestado atención a cómo los nominales (actores), adjuntos (caracterizaciones) y formas verbales (acciones) que se utilizan en la prensa 'construyen' al agresor, a la víctima y al testigo, y 'perspectivizan', en última instancia, su representación.

\subsection{Actores}

Para Van Leeuwen (1996), las formas de nominación de los actores sociales constituyen mecanismos claros de inclusión o exclusión social y mantienen un alto grado de dependencia con el contexto en el que se producen. Por tanto, la denominación se convierte en un aspecto prioritario en el estudio de la representación social de los actores en el dominio periodístico.

Los campos denominativos nos permiten determinar cuáles son las representaciones semánticas que los vehiculan y que se encuentran tras ellos, induciendo categorizaciones distintas de inmigrantes y extranjeros o, particularmente, de las mujeres inmigrantes en nuestro país, asociadas a numerosos 'prejuicios' y 'estereotipos' que se reproducen en los textos publicados en los medios. En este sentido, nos interesa saber cuáles son las variantes designativas que con mayor frecuencia se utilizaron en la prensa española y ecuatoriana para referirse al agresor, a la víctima y al testigo del ataque racista en el tren de Barcelona.

\subsubsection{Caracterizaciones}

Las denominaciones suelen completarse con caracterizaciones que pueden limitar o ampliar su contenido semántico. Estas calificaciones consisten en valoraciones positivas o negativas que pueden estar más o menos generalizadas en relación con ciertos individuos o grupos sociales y nos proporcionan rasgos significativos en el análisis de cómo son construidos en el discurso y socialmente representados. 
Tabla I. Medio, nacionalidad, ámbito y fechas de la información.

\begin{tabular}{|l|l|l|l|}
\hline Nombre & Nacionalidad & Ámbito & Fechas \\
\hline Hoy & Ecuador & Nacional & $\begin{array}{l}25 / 10 / 2007 \\
26 / 10 / 2007\end{array}$ \\
\hline Diario Hispano Ecuatoriano & \multirow{2}{*}{ Ecuador } & Nacional & $\begin{array}{l}23 / 10 / 2007 \\
24 / 10 / 2007\end{array}$ \\
\hline El Clarín & \multirow{2}{*}{ Ecuador } & $\begin{array}{l}\text { Local (Babahoyo, Los } \\
\text { Ríos) }\end{array}$ & $26 / 10 / 2007$ \\
\hline CRE Satelital Ecuador & Ecuador & Local (Guayaquil) & $22 / 10 / 2007$ \\
\hline Diario Correo & Ecuador & Local (Machala) & $24 / 10 / 2007$ \\
\hline \multirow{2}{*}{ El País } & \multirow{2}{*}{ España } & Nacional & $22 / 10 / 2007$ \\
& & & $24 / 10 / 2007$ \\
\hline \multirow{2}{*}{ El Mundo } & \multirow{2}{*}{ España } & Nacional & $23 / 10 / 2007$ \\
& & \multirow{2}{*}{ Nacional } & $24 / 10 / 2007$ \\
\hline \multirow{2}{*}{ El Avui } & \multirow{2}{*}{ España } & Local (Cataluña) & $\begin{array}{l}22 / 10 / 2007 \\
25 / 10 / 2007 \\
22 / 10 / 2007 \\
23 / 10 / 2007\end{array}$ \\
\hline El Ideal & \multirow{2}{*}{ España } & Local (Andalucía) & $\begin{array}{l}23 / 10 / 2007 \\
24 / 10 / 2007 \\
26 / 10 / 2007\end{array}$ \\
\hline
\end{tabular}

\subsubsection{Acciones}

Siguiendo los planteamientos de Ribas (2008), el tercer componente que interviene en la descripción de los actores sociales que participan en la escena que analizamos se refiere a las 'acciones'. Estas acciones coinciden, según la autora, con los roles que desempeñan sus protagonistas $y$, por tanto, constituyen un recurso indispensable en su construcción socio-discursiva.

\section{Corpus}

El material que utilizamos en este trabajo está integrado por dos subcorpus de textos periodísticos que han sido contrastados (ver Tabla I). El primero está compuesto por diez textos (noticias y artículos de opinión) de la prensa ecuatoriana, aparecidos entre el 22 y el 26 de octubre de 2007, pertenecientes a cinco diarios de difusión nacional y de libre acceso en la Red: Hoy y Diario Hispano Ecuatoriano, ambos editados en Quito; El Clarín, editado en Babahoyo (Los Ríos); CRE Satelital Ecuador, medio digital de Guayaquil; y el Diario Correo, de Machala.
El segundo está constituido por diecisiete textos (noticias y artículos de opinión) que aparecieron en la prensa española nacional (El País, El Mundo y $A B C$, con sede en Madrid) y local (El Avui de Cataluña y El Ideal de Andalucía), publicados también entre el 22 y el 26 de octubre. Los artículos se extrajeron de las ediciones electrónicas de dichos periódicos. Dado que las fuentes poseen bases ideológicas de distinta índole, este corpus heterogéneo proporciona un amplio abanico de aproximaciones a los hechos. Las búsquedas han sido realizadas en las bases de datos de las publicaciones a partir de las siguientes palabras clave: 'Sergi Xavier', 'joven ecuatoriana' y 'agresión cercanías'.

\section{Resultados}

En este apartado nos ocupamos de las representaciones socio-discursivas que se desprenden del análisis de las denominaciones, caracterizaciones y acciones que se le atribuyen a cada uno de los actores (agresor, víctima y testigo) presentes en el ataque racista. En primer lugar, atendemos a la prensa ecuatoriana $y$, en segundo, a la española, para finalmente comparar los textos que aparecieron en los dos grupos de medios escritos. 


\section{I. Representaciones socio-discursivas en la prensa ecuatoriana}

\section{I.I. Representación del agresor}

Entre las unidades designativas que se refieren al agente de la agresión en los textos que componen nuestro corpus de prensa ecuatoriana, la que registra el mayor índice de aparición es 'agresor' (27). Esta designación implica un rol agente y activo por parte de quien emprende la acción: 'el autor del ataque racista' (2). Esta misma dinámica es la que revela el calificativo 'culpable' (2) en forma sustantivada, con el que se ponen de relieve la responsabilidad y la deliberación en las acciones efectuadas.

Seguida en número de veces (I3), es habitual que se designe al agresor por su propio nombre: 'Sergi Xavier Martí Martínez', 'Marti', etc. Como anécdota, en una ocasión se asocia la palabra 'Locandis' con el agresor, en la prensa ecuatoriana. Al parecer, este es el apodo con el que conocen en su pueblo, Santa Coloma de Cervelló, al joven que agredió a la chica en el tren de cercanías. En efecto, esta denominación está semánticamente emparentada con el calificativo 'loco'. Llama la atención que la falta de juicio y racionalidad, como veremos, están presentes entre las caracterizaciones más recurridas en la prensa para describir el carácter de este actor.

En los textos ecuatorianos se reproduce, asimismo, la polarización entre 'Ellos' y 'Nosotros'. Así, por ejemplo, ocurre cuando este actor es mostrado en la prensa ecuatoriana como 'el (agresor) español' o 'el ciudadano español' en oposición a la víctima ('nuestra compatriota'). En estos casos, se aprecia una presentación positiva de la comunidad ecuatoriana frente a la representación negativa de la comunidad española de acogida.

De hecho, el tema de la agresión en el tren de cercanías catalán llega a extenderse a los:

permanentes maltratos que reciben los ecuatorianos que diariamente acuden a las oficinas de la embajada española en Ecuador para realizar sus trámites o solicitar un visado ("Indignación en Ecuador por agresión a joven emigrante en España”, Diario Hispano Ecuatoriano, Quito, 23 de octubre de 2007).
En otro medio escrito ecuatoriano leemos:

Asimismo, la Cancillería hizo patente su preocupación y extrañeza por la reiterada negativa a conceder visados a estudiantes ecuatorianos de niveles superiores, que a pesar de haber obtenido matrículas y/o becas en institutos españoles, cumplidos los requisitos reglamentarios y que aún más, según expresiones de numerosos afectados, se agravan por la sistemática atención displicente que reciben por parte del personal del Consulado General de España ("Ecuador emite nota diplomática de protesta por liberación de agresor", Diario Hispano Ecuatoriano, Quito, 24 de octubre de 2007).

Este mismo fenómeno de extensión de un hecho particular lo observamos en las referencias a otros incidentes xenófobos y racistas que tienen lugar en España. A partir de una agresión muy concreta, la del tren de cercanías contra la chica ecuatoriana de quien desconocemos su identidad por ser menor de edad, y de una conducta concreta, la del agresor, se produce una generalización que llega a aplicarse a todo el país de acogida:

El congresista enfatizó que esta agresión refleja actitudes irracionales de intolerancia y de barbarie, claramente xenofóbicas y racistas contra personas que se encuentran, temporalmente, en ese país, aportando en forma significativa al desarrollo socioeconómico español ("Congreso ecuatoriano condena agresión a ecuatoriana”, Diario Hispano Ecuatoriano, Quito, 24 de octubre de 2007).

En diálogo con Noti Mundo y Ecuadorinmediato. com, Jiménez sostuvo que este hecho no es aislado, ya que muchos casos de este tipo no son denunciados por las víctimas por temor o porque no tienen las pruebas del caso. [...] Agregó que en España hay "un racismo solapado". "Todos los españoles aquí dicen: yo no soy racista, pero de una u otra forma en el trabajo, en los sitios públicos, todas las opiniones" se habla en contra de los extranjeros, dijo. ("Asociación de Emigrantes "Rumiñahui" pide justicia para ecuatoriana”, Diario Hispano Ecuatoriano, Quito, 24 de octubre de 2007). 
Uno de los titulares aparecidos en el Diario Clarín a consecuencia de la agresión a la joven ecuatoriana reza:"Denuncian que el ataque racista en Barcelona no es un caso aislado". La impersonalización del título desaparece en el subtítulo donde leemos:

Organizaciones no gubernamentales españolas dijeron que hay 'muchísimas' agresiones xenófobas como la que sufrió una ecuatoriana en el subte, pero generalmente son silenciadas". Citaron los casos de dos africanos, uno que quedó tetrapléjico [Miwa Buene] y otro que sufrió la perforación de un pulmón [Bakari D.] (26 de octubre de 2007).

En el ejemplo anterior se reproduce un sofisma de inducción como es la 'falsa generalización': se parte de la afirmación de que una propiedad (el racismo) es compartida por varios individuos de un conjunto (el español) y se concluye que todos los elementos de ese conjunto (los españoles) poseen esa cualidad, cuando en realidad no puede tenerse esa evidencia sin tener la información acerca de los miembros restantes. Además, se confunde lo que es accidental con aquello que es esencial, en otras palabras, lo que es relativamente verdadero con lo que es absolutamente verdadero.

En el mismo texto de Clarín encontramos alusiones a la carencia de medidas judiciales sólidas en España en relación con agresiones xenófobas. Deficiencias del sistema jurídico que, por otra parte, salen a relucir a raíz de la impunidad en que queda el agresor:

Según Begoña Sánchez, "falta sensibilidad a nivel judicial sobre el tema, a la hora de considerar el agravante de racismo". "En el Código Penal está tipificado el agravante de racismo, pero solo cuando hay lesiones", agregó.

La dirigente señaló que "normalmente los ataques racistas se quedan en falta, porque no se aplica la normativa europea en esta materia, $y$ es la víctima la que tiene que demostrar que hay lesiones por un móvil racista”.

En este ejemplo concreto, se reproduce un sofisma de cambio temático en el que la argumentación es correcta en sí misma, pero no se trata del punto que se está discutiendo (la agresión) y acerca del cual se pretende extraer una conclusión. En consecuencia, se produce una suplantación de tesis: se desorienta el tema del racismo en España para alegar razones sobre un punto que no se cuestiona, como es la falta de medidas judiciales que se aplican por este tipo de delitos.

Ocasionalmente, la cualidad resaltada en el agresor es la de hostilidad hacia los extranjeros y ello se pone de manifiesto en el calificativo sustantivado 'el xenófobo' (3). También encontramos expresiones, como 'individuo de $2 \mathrm{I}$ años' (6), cuyo adjunto pone el acento en la edad, para establecer una comparación con la de la víctima ('una menor de 16 años'). Menos abundantes, pero existentes, son las designaciones que hacen referencia a la naturaleza humana del agresor:'el/un hombre', 'un joven'.

En la caracterización de este actor predominan, sin duda, los descalificativos que construyen la imagen negativa del agresor: 'cobarde', 'rabioso', 'vejatorio', 'altivo', 'cargado de antecedentes penales', 'condenable', 'conflictivo', 'degradante', 'descontrolado', 'insultante', 'intolerante', 'salvaje' y 'violento'.

Las acciones que se le atribuyen se relacionan indefectiblemente con la agresión física y verbal: la más frecuente 'golpear' (8), seguida de 'insultar', 'patear', 'tocar los pechos/senos', 'emitir frases xenófobas' y 'arremeter'. Los textos aparecidos en la prensa ecuatoriana atienden, a veces, al modo como el agresor cometió las acciones violentas que son condenadas: injustificadamente ('sin mediar motivo') e irracionalmente ('brutalmente').

Finalmente, los calificativos empleados para reprobar la agresión también son aplicables al agresor:'salvaje', 'degradante', 'vejatoria', 'condenable' o, en palabras del presidente del Gobierno español, 'deleznable' (ver Tabla 2).

\section{I.2. Representación de la víctima}

A la agredida se le asigna generalmente un rol pasivo y paciente, como sugieren las expresiones 'víctima' ('de este atentado', 'de esta agresión','del racismo'), 'afectada' o 'agredida'. Sin embargo, las designaciones que aparecen en los textos recogidos redundan en la edad:'la menor' (20), 'la joven' (20),'la adolescente' (4) y 'la niña' (2).

La caracterización que recibe insiste igualmente en la edad y en la procedencia. Al primer grupo pertenecen los adjuntos 'de 16 años' (8), 'joven, 
Tabla 2. Representación del agresor en la prensa de Ecuador.

\begin{tabular}{|c|c|c|c|c|c|}
\hline \multicolumn{2}{|c|}{ Denominación } & \multicolumn{2}{|c|}{ Caracterización } & \multicolumn{2}{|l|}{ Acción } \\
\hline Agresor & 27 & De 2 I años & 6 & Golpear & 8 \\
\hline Sergi Xavier Martí & & Español & 2 & Insultar & 5 \\
\hline Martínez, Martí, etc. & 13 & Cobarde & 2 & Patear & 4 \\
\hline El xenófobo & 3 & Rabioso & 2 & Tocar los pechos/senos & 4 \\
\hline El autor del ataque & 2 & Vejatorio & 2 & Emitir frases xenófobas & 2 \\
\hline El culpable & 2 & Altivo & I & Arremeter & I \\
\hline Individuo & 2 & Cargado de & & & \\
\hline Un hombre & 2 & antecedentes penales & I & & \\
\hline Un joven & 2 & Condenable & I & & \\
\hline El ciudadano & I & Conflictivo & I & & \\
\hline Locandis (apodo) & I & Degradante & I & & \\
\hline & & Descontrolado & I & & \\
\hline & & Insultante & I & & \\
\hline & & Intolerante & I & & \\
\hline & & Salvaje & I & & \\
\hline & & Violento & I & & \\
\hline
\end{tabular}

Tabla 3. Representación de la víctima en la prensa de Ecuador.

\begin{tabular}{|lr|lr|lr|}
\hline \multicolumn{2}{|c|}{ Denominación } & \multicolumn{2}{c|}{ Caracterización } & \multicolumn{2}{c|}{ Acción } \\
\hline La menor & 20 & Ecuatoriana & I5 & Ser maltratada, & 5 \\
La joven & 20 & De I6 años & 8 & agraviada, insultada, & \\
Víctima (de este & 13 & Inmigrante & 3 & amenazada, golpeada & \\
atentado, de esta & & Nacida en Guayaquil & 3 & Sufrir las agresiones/ & 5 \\
agresión, del racismo) & & Emigrante & 2 & ataque & \\
La ecuatoriana & 10 & Agraviada & I & Sufrir una psicosis & \\
La adolescente & 4 & Amenazada & I & \\
Afectada & I & Golpeada & I & \\
Agredida & 2 & Indefensa & I & \\
La niña & 2 & Insultada & I & \\
Nuestra compatriota, la & 2 & Maltratada & 1 & \\
joven compatriota & & & & \\
\hline
\end{tabular}

menor', 'indefensa'; al segundo se adscriben 'ecuatoriana' (I5), 'nacida en Guayaquil', 'emigrante', 'inmigrante', entre otros. Además, vuelve a presentarse una sociedad parcelada en grupos ('ellos'/ 'nosotros') en designaciones del tipo 'nuestra compatriota' o 'la joven compatriota'.

El carácter paciente que asume la víctima se resuelve por medio de participios como 'maltratada', 'agraviada', 'insultada', 'amenazada' o 'golpeada', intensificados a veces por adverbios modales del tipo 'brutalmente', que se hacen corresponder con 'sufrir las agresiones' y las consecuencias de estas:

la menor agredida sufre de una psicosis que le impide no solo salir a la calle, sino denunciar la agresión" ("Asociación de Emigrantes "Rumiñahui" pide justicia para ecuatoriana. Diario Hispano Ecuatoriano, Quito, 24 de octubre de 2007).

En suma, las designaciones que recurrentemente recibe la víctima suelen combinar tres aspectos: la minoría de edad (I6 años), el origen (Ecuador) y el maltrato al que ha sido sometida por un español (ver Tabla 3).

Las referencias que encontramos sobre la víctima cumplen principalmente la función de distinguir a unos grupos sociales de otros. No solo hacen hincapié en la diferencia de edad entre el agresor y la víctima, sino que establecen una clara distinción entre nacionalidades: españoles y ecuatorianos. 
Tabla 4. Representación del testigo en la prensa de Ecuador.

\begin{tabular}{|ll|ll|ll|}
\hline \multicolumn{2}{|c|}{ Denominación } & \multicolumn{2}{c|}{ Caracterización } & \multicolumn{1}{c|}{ Acción } \\
\hline Testigo & 2 & Colgado de sus & 2 & Contemplar, mirar la agresión & I \\
Cómplice involuntario & I & audífonos & Estar fuera del mundo & I \\
El otro hombre & I & Argentino & I & No hacer & I \\
El otro pasajero & I & Incompasivo & I & No querer escuchar & I \\
Hombre joven & I & Joven & I & Volver el rostro hacia otro & 2 \\
Joven & 2 & Miedoso, cobarde & I & lado, no querer ver, no mirar \\
& & Pasivo, indiferente, & a la agredida, mirar al no \\
& mudo, silencioso & & espacio, mirar hacia otro lado \\
\hline
\end{tabular}

\section{I.3. Representación del testigo}

El tercer actor es nombrado como 'testigo', 'hombre joven' y 'cómplice involuntario'. Estas denominaciones suelen aparecer matizadas por caracterizaciones referentes a la nacionalidad ('argentino'), pero destacan su condición de 'pasivo', 'indiferente', 'mudo' y 'silencioso'. Calificaciones de las que se derivan otras como son: 'miedoso', 'cobarde' e 'incompasivo'. En cuanto a las acciones, prevalecen las que se marcan negativamente: 'no querer ver', 'no querer escuchar', 'no mirar a la agredida', 'no hacer nada'. Por otro lado, las que no tienen marcas de negación se relacionan igualmente con la indeferencia de la cual es acusado, con gran frecuencia, el testigo de la agresión en los textos: 'volver el rostro','mirar hacia otro lado', 'mirar al no espacio' y 'estar fuera del mundo'.

En síntesis, el papel que le asigna la prensa ecuatoriana al testigo de la agresión participa por igual de algunos de los rasgos que les son atribuidos al agresor $y$ a la víctima. Su pasividad y su disposición paciente, el temor reflejado en el semblante, la expresión de pasmo y desconcierto ante la agresión lo relacionan con la víctima. Sin embargo, su aparente indiferencia ante los hechos lo convierte hasta cierto punto en cómplice del agresor.

Esta dualidad de la que participa el testigo en su caracterización permite trazar un paralelo con la actitud predominante en las sociedades avanzadas de nuestros días: la observación de las injusticias y la indignación por las mismas, pero la falta de denuncia y manifestación son comportamientos que el testigo comparte con el resto de la sociedad desarrollada.

Cerca de la cámara, un hombre joven, que está colgado de sus audífonos, mira la agresión y vuelve el rostro hacia otro lado: no quiere ver. Se puede intuir que no es indiferencia: es miedo, tal vez cobardía, vergüenza. $O$ los tres sentimientos juntos y también indiferencia. El agresor se va. El otro hombre el de los audífonos no mira a la agredida, mira al no espacio, no hace ningún gesto que insinúe un interés por la víctima, menos un acto, aún tardío de solidaridad o quizá de compasión.

[...]

El testigo, tan joven como el agresor y la agredida es un cómplice involuntario, pero cómplice al fin. No quiere escuchar los sonidos del mundo: está fuera del mundo, está "colgado" de sus audífonos. ¿Qué pensará ahora de su pasividad? Debería pedir perdón a gritos. ¿No es acaso la posición de las mayorías silenciosas, de las que miran hacia otro lado para no escuchar el grito de las víctimas, ni ver el rostro de los agresores?

[...]

Las imágenes del video del metro de Barcelona son un espejo: allí estamos como testigos mudos, como agresores y víctimas (C. Arcos Cabrera: “Los rostros del racismo", Hoy Online, Quito, 25 de octubre de 2007).

Además de su pasividad ante la agresión y de su juventud (24 años), el testigo es caracterizado, en los textos ecuatorianos, por su nacionalidad:'argentino'. Comparte pues con la víctima el no ser natural de España y, más particularmente, su procedencia latinoamericana (ver Tabla 4).

\subsection{Representaciones socio-discursivas en la prensa española}

\subsection{Representación del agresor}

En los textos que componen el corpus de la prensa española hemos localizado distintas denominaciones empleadas para designar a los tres actores sociales involucrados en el ataque. 
Tabla 5. Representación del agresor en la prensa de España.

\begin{tabular}{|lr|lr|lr|}
\hline Denominación & & Caracterización & & Acción \\
\hline Agresor & 38 & De 2I años & I7 & Insultar & 24 \\
El joven & 34 & Vecino de Santa Coloma & 7 & Golpear & 16 \\
Sergi Xavier M. M. & 25 & de Cervelló & & Dar patadas & 13 \\
Individuo & 6 & Español & 2 & Tocar los pechos/senos & 7 \\
El (presunto) autor (del & & Violento & 2 & Dar puñetazos & 6 \\
ataque/agresión) & 5 & Alto & I & Fijarse & 5 \\
El arrestado & 5 & Imprevisible & I & Dar una paliza & 4 \\
El detenido & 5 & Racista & I & Amenazar & 4 \\
El imputado & 3 & & & Increpar & 3 \\
Sergio Javier M. M. & 3 & & & \\
El chico & 2 & & & \\
El sospechoso & 1 & & & \\
Viajero & I & & & \\
\hline
\end{tabular}

La persona que ostenta un mayor protagonismo en los periódicos fue el agente de la agresión. En el corpus analizado, las unidades designativas más recurrentes son 'agresor' (38), 'joven' (34) y, con menor frecuencia, su nombre propio (28), 'Sergi Xavier M. M.', que aparece en todos los periódicos en catalán, a excepción del $A B C$, que lo traduce al español (Sergio Javier M. M.).

Otras designaciones que le son atribuidas al agente del ataque están relacionadas con el arresto o la detención ('arrestado', 'presunto autor', 'detenido', 'sospechoso','imputado'), con su edad ('joven, chico'), con su condición de pasajero en el tren ('viajero') o, en términos más neutros, se refieren a él como ‘individuo’ (ver Tabla 5).

En repetidas ocasiones (16), se alude a su edad mediante el adjunto 'de $2 \mathrm{I}$ años' en contraste con la edad de la chica, cinco años menor que el agresor $y$, por lo tanto, menor de edad. Asimismo, es llamativo que la prensa española se refiera al chico como 'vecino de Santa Coloma de Cervelló' (7) y que en la prensa local (El Ideal y El Avui) se mencione en dos ocasiones su origen ('español'). El hecho de vincular al agresor con una zona muy concreta de España y caracterizarlo únicamente como español podría deberse a que no se quiera reconocer al agresor como miembro prototípico del endogrupo. No obstante, sería necesario realizar indagaciones más detalladas para valorar esta posibilidad.

Las cualidades que se le asignan explícitamente son, en general, escasas en los textos que componen el corpus de prensa española. En un artículo de opinión de El País se le atribuyen las caracterizaciones de 'alto', 'violento' e 'imprevisible'. Asimismo, en un artículo de El Mundo es comparado con el grupo violento y racista de los skin-heads, tachándolo de 'cobarde'. También es tildado de 'racista' en unas declaraciones textuales de la agredida. Sin embargo, en uno de los artículos del $A B C$ aparecido en portada, se completa la caracterización del agresor de la siguiente manera:

El individuo [...] no reúne, al parecer, el perfil de ser miembro o militante de una organización xenófoba y racista, sino que todo indica que es un individuo que actúa con altas dosis, a veces gratuitas, de violencia.

Por otra parte, en el diario El Ideal se cuestiona la naturaleza racista del agresor hasta el punto de convertirlo en víctima de su propia agresión:

El psiquiatra Alfons Icart [...] ha puntualizado que en la agresión a la chica ecuatoriana, no se sabe si la agresión se produce por racismo o porque se está agrediendo a sí mismo, en un momento de confusión por alcohol y drogas.

En consecuencia, a pesar de que la tendencia predominante en la prensa española califique de racista la agresión física y los insultos proferidos, no se le asigna directamente esta cualidad al autor del ataque. De hecho, tal y como observamos en las citas anteriores, se llega a anular el rasgo 'racista' (en el fragmento del $A B C$ ) y es parcialmente victimizado (en el artículo de El Ideal). En relación con los otros implicados, el agresor es a quien más verbos agentivos se le atribuyen y su ataque racista en el convoy es descrito 
minuciosamente ('insultar', 'amenazar', 'golpear', 'dar patadas', 'dar puñetazos', 'tocar los pechos', 'dar una paliza', 'increpar', 'fijarse'). A menudo, estas acciones se completan con adverbios que caracterizan la manera como perpetró sus ataques ('agresivamente', 'brutalmente').

Los hechos aparecen también acompañados de descalificativos como 'brutal' (8), 'racista' (8), 'con claros tintes racistas', 'que tiene tintes de ser un ataque racista', 'inexplicable' (2), 'para provocar repugnancia', 'caso grave' o 'dramático'. Las autoridades que aparecen citadas en el corpus son el juez que instruyó el caso, quien lo condena como un hecho 'deleznable' y 'repugnante', y el presidente del Gobierno, que utiliza también la palabra 'deleznable'. No obstante, los calificativos que se emplean para describir la agresión no son demasiado abundantes y proporcionan a los textos un tono, a nuestro juicio, poco comprometido.

Según los estudios de van Dijk sobre la ideología racista en la prensa $(1997,1998,2007)$, existe la tendencia de desenfatizar en el endogrupo los aspectos negativos que presenta dicho colectivo. Cabe señalar, que en uno de los artículos de El País la acción del agresor se ve notablemente atenuada por medio de recursos discursivos -como la nominalización y la omisión de información- que desde nuestro punto de vista resultan significativos, sobre todo, por ocupar el titular y el subtítulo de la noticia. El titular topicaliza el artículo como sigue: "Agresión racista en el tren de Barcelona". Acto seguido, el subtítulo reproduce que "insultó" a la víctima y menciona únicamente al final del texto que la agredió físicamente. En este caso, entendemos que es a partir de la macroestructura de la noticia desde donde, a través de estos recursos, se está mitigando y -hasta cierto punto- ocultando la violencia con que el agresor atacó a la menor.

El corpus recoge también los artículos que aparecieron en prensa pocos días después de que el ataque saliera a la luz pública. La prensa realizó una entrevista al agresor donde se excusaba diciendo que actuó de aquella manera debido al estado de embriaguez en el que se encontraba. De los periódicos que forman el corpus, la mayoría citan al agresor textualmente y no incluyen comentarios al respecto, únicamente El Mundo, en tono irónico, le resta credibilidad a sus palabras: "Lo que no explicó (Sergi) es cómo estando tan ebrio no solo no se tambaleaba, sino que pudo dar una patada que hubiera firmado el propio Bruce Lee”.
En suma, el agresor es la persona que goza de más protagonismo en los artículos de prensa española,ya que es el actor más nombrado y al que se le atribuyen más acciones. Se le caracteriza principalmente en función de su edad, de su lugar de residencia y de las acciones realizadas en el tren. De igual modo, cabe indicar que en algunos textos el agresor goza de cierto grado de exculpación, dado que se oculta la violencia con la que perpetró la agresión (es el caso de topicalización en el titular de El País) y se mitiga su responsabilidad, convirtiéndolo a él mismo en víctima de su propia conducta (como hemos visto en el fragmento de El Ideal).Además, a pesar de que tanto sus acciones como los insultos proferidos fueran racistas, él no es calificado de esta forma: simplemente se construye una imagen de persona violenta. De todos los medios consultados, el único periódico que adopta una actitud más crítica ante la agresión es el diario El Mundo, donde se desacredita la justificación que el agresor hizo del ataque.

\subsubsection{Representación de la víctima}

Las unidades designativas más comunes para referirse a la víctima de la agresión son 'menor' (46) y 'chica' (29). Estos sustantivos suelen aparecer posmodificados por adjetivos o grupos adjetivos que aluden a su lugar de origen y subrayan el hecho de que la agresión sea doblemente injusta. En primer lugar, por tratarse de una menor edad $y$, en segundo lugar, por pertenecer esta a una minoría étnica. No obstante, en la mayoría de los textos se hace énfasis en la nacionalidad extranjera de la joven, tal y como lo demuestra la repetida alusión a su origen, en ocasiones, más de cuatro veces en un mismo artículo. Asimismo, es común que se denomine a la chica como 'víctima' (22). Acorde con esta designación, se le atribuye un rol pasivo en la descripción de la escena de la agresión, siendo en la mayoría de los textos la receptora inactiva de los ataques. Únicamente en un artículo de El Mundo se le asigna un mínimo grado de participación en la escena ('Ella intenta evitar que le vuelva a golpear'). La prensa española describe el estado psicológico de la chica tras la 'pesadilla' sufrida y comenta que una vez pasada esta 'terrible' experiencia, la víctima entró en 'estado de shock'; por lo que durante los días posteriores comenzó un tratamiento psicológico, debido al miedo que seguía sintiendo. Las cualidades que se le asignan en el momento de la agresión son 'resignada' y 'asustada' (ver Tabla 6).

En el periódico $A B C$ se culpabiliza indirectamente a la víctima por intercambiar miradas con el agresor. 
Tabla 6. Representación de la víctima en la prensa de España.

\begin{tabular}{|lr|lr|ll|}
\hline \multicolumn{1}{|c|}{ Denominación } & \multicolumn{2}{c|}{ Caracterización } & \multicolumn{2}{c|}{ Acción } \\
\hline La menor & 46 & Ecuatoriana & 38 & Entrar en estado de & I \\
La chica & 29 & De I6 años & 10 & shock & \\
Víctima & 22 & Suramericana & 4 & Mirar con extrañeza al & I \\
la adolescente & 12 & Inmigrante & 2 & agresor & \\
La joven & 4 & Asustada & 1 & Sufrir una pesadilla & I \\
Ecuatoriana & I & De origen & 1 & & \\
& & hispanoamericano & & & \\
& & Resignada & 1 & & \\
\hline
\end{tabular}

Tabla 7. Representación de la testigo en la prensa de España.

\begin{tabular}{|ll|ll|}
\hline \multicolumn{1}{|c|}{ Caracterización } & \multicolumn{2}{|c|}{ Acción } \\
\hline De origen argentino & 2 & Disimular & I \\
Sudamericano & 2 & Mirar (de refilón) & I \\
Inmigrante & I & No ayudar (a la víctima), & \\
Inmóvil & I & No mirar (la escena), & \\
Impávido & I & No hacer ningún intento & I \\
Impasible & I & por parar la agresión & \\
& & No interceder & I \\
\hline
\end{tabular}

De esta forma, en uno de los artículos del $A B C$ se subraya en un subtítulo que el detonante de los hechos fue la mirada de la chica: "El detonante: la mirada". Posteriormente, se explica de la siguiente manera: "La mirada de la adolescente, que no intercambió ninguna palabra con su agresor, desencadenó, al parecer, la violencia con la que actuó Sergio". El diario catalán Avui nos sirve para contrastar esta información, donde se dice que la conversación que el agresor mantenía por su teléfono móvil tenía:

Un clar contingut recista i violent, cosa que va provocar que la menor el mirés amb estranyesa. Els investigadors, però, estan convençuts que el distingut la va agredir pel sol fet de ser ecuatoriana"

No obstante, en una entrevista ofrecida por la chica a la emisora colombiana Radio Caracol, esta asegura que no intercambió 'ni miradas' con su agresor. Se podría decir entonces que en uno de los periódicos del endogrupo se produce el fenómeno de culpar a la víctima (blaming the victim) en el cual se le atribuye a este actor, de modo más o menos indirecto, un mayor o menor grado de culpabilidad. Este es un rasgo propio de los discursos racistas.

\subsubsection{Representación del testigo}

El testigo aparece mentado en nueve de los diecisiete artículos que componen el corpus español. Se le designa como 'joven', 'chico' y 'adolescente', compartiendo con el agresor y víctima la caracterización en función de la edad. Otras designaciones menos habituales son 'el tercer pasajero', 'testigo' y 'tercera persona' (ver Tabla 7). Asimismo, el testigo es caracterizado como no natural de España, refiriéndose a él como 'inmigrante', 'de origen sudamericano', 'de origen argentino'. Esta característica es la más resaltada en relación con esta persona. En un artículo de El Mundo se enfatiza esta cualidad de la siguiente manera: "Un dato muy importante: también es sudamericano. Está sentado y seguirá así durante toda la secuencia. El chico disimula. Es la mirada del miedo".

Salvo en El País, 'en el resto de los periódicos que componen el corpus en español' (El Mundo, ABC, El Avui y El Ideal), es precisamente su condición de inmigrante la que se emplea como justificación para la ausencia de reacción del testigo. Además, se le construye como potencial víctima de los ataques del agresor:

Había otro adolescente de origen suramericano en el vagón, que presenció los golpes e insultos 
a la chica sin ayudarla por miedo a ser también víctima de la ira del agresor ("Detienen a un joven que dio una paliza a una menor por ser ecuatoriana", $A B C$, Barcelona, 23 de octubre de 2007).

Muy cerca de la adolescente había otro joven de origen suramericano que no hizo según las imágenes, ningún intento por parar la agresión, aunque posiblemente no actuara por miedo a recibir algún golpe ("Detenido un joven por agredir e insultar a una menor ecuatoriana en un tren de Barcelona", El Ideal, 23 de octubre de 2007).

Tan solo un artículo de opinión de El País critica la pasividad del testigo calificándola de 'incomprensible', así como el hecho de que los medios de comunicación no considerasen oportuno criticarlo.

El testigo comparte con la víctima, aparte del origen sudamericano, el rol pasivo que le es atribuido. La agentividad de la que se dota a este individuo es escasa o nula. Además, las acciones son descritas por medio de formas negativas. Es decir, se comentan negativamente las acciones que se esperarían del testigo: 'sin ayudarla', 'ni siquiera mira la escena', 'no hizo ningún intento por parar la agresión', 'no intercedió'). Asimismo, la pasividad se desprende del modo como el testigo presenció el ataque: 'inmóvil', 'impávido' e 'impasible’.

\subsection{Análisis contrastivo de las representaciones socio-discursivas en la prensa ecuatoriana y española}

Tanto los medios escritos españoles como los ecuatorianos informan de un mismo suceso: el ataque xenófobo que tuvo lugar en un tren de cercanías de Barcelona. Sin embargo, en ese proceso de información asistimos a una inevitable selección de fuentes, argumentos y palabras utilizadas en la denominación, caracterización y acciones atribuidas a los actores. Este proceso de selección lingüística supone el tratamiento de una realidad social sujeto a distintos patrones ideológicos y cognitivos.

Si prestamos atención a las denominaciones, existe cierta consonancia en cuanto a la frecuencia de aparición o número de veces en que la víctima y el agresor son nombrados en la prensa ecuatoriana y española. En el primer caso, la víctima es mencionada hasta 74 veces, mientras que el agresor es apelado en 55 ocasiones. En el corpus de prensa española, contrariamente, el agresor es citado en 128 ocasiones, apelándose a la víctima en II 4 ocasiones. En suma, registramos un total de 188 apariciones para la víctima y un total de 183 para el agresor en ambos subcorpus.

Por tanto, el interés hacia el agresor es sensiblemente superior al que se manifiesta por la víctima en la prensa española y, a la inversa, es creciente la afinidad hacia la víctima en la prensa ecuatoriana. Esto es, tras el leve predominio denominativo que apreciamos en cada uno de los subcorpus, subyace una cuestión de tipo social, como es el origen geográfico o la pertenencia a una determinada comunidad. En otras palabras, la propensión en las referencias a la víctima y al agresor en cada caso puede interpretarse como un efecto de inclinación del endogrupo (ecuatoriano y español, respectivamente).

Por otra parte, comparando los resultados totales, los índices de aparición son similares en los dos subcorpus. Esto nos lleva a plantearnos si verdaderamente existe un desajuste en cuanto al protagonismo general que tienen el agresor y la víctima en la prensa. Tanto la carga denominativa como el número de acciones que se le atribuyen al agresor en la prensa española (82) lo convierten en el auténtico protagonista de los hechos. La misma tendencia observamos al enfrentar el número de acciones que son asignadas al agresor en la prensa ecuatoriana (24), frente a las acciones que se adjudican a la víctima (I I). El testigo, en ambos casos, es quien percibe un menor grado de protagonismo ( 5 acciones le son atribuidas en la prensa ecuatoriana, 3 en la española). En conclusión, son pocas las dudas acerca del papel principal con el que se representa al agresor en la prensa ecuatoriana y española. Esto nos permite afirmar que es el agresor quien participa del rol agente y activo en la escena.

La atenuación de las responsabilidades del agresor que observamos en la prensa española no es tal en la prensa ecuatoriana, donde se hace mayor hincapié en la agentividad y la deliberación en las acciones racistas efectuadas por este. No obstante, algunas veces, la generalización resulta extrema en los textos ecuatorianos, ya que de un hecho particular realizado por un español se infiere que todos los españoles participan de la cualidad de racistas y el asunto se lleva aún más lejos al afirmar que el sistema judicial español es deficitario en materia de racismo e inmigración. 
Una de las diferencias más palpables es la escasez de adjetivos que se le atribuyen tanto al agresor como a sus acciones, en el corpus de prensa española. En cambio, en el corpus ecuatoriano abundan los descalificativos dirigidos al agresor y a sus actos. Esto puede apuntar a la ya comentada polarización ideológica entre 'Ellos' y 'Nosotros', según la cual las acciones negativas se enfatizan si provienen del exogrupo, mientras que tienden a atenuarse en el endogrupo. Esta mitigación se aprecia de forma muy clara, como comprobamos, en un artículo de $\mathrm{El}$ Ideal donde se llegó incluso a victimizar al agresor. Por otro lado, resulta relevante en nuestro análisis que en la prensa ecuatoriana se haya traspasado la cualidad racista del agresor a toda la comunidad española, culpabilizándola en última instancia de la agresión.

Tanto las acciones que se le asignan al agresor en la prensa ecuatoriana, como la caracterización que recibe, coinciden en un aspecto: la irracionalidad. En este sentido, la categorización del agresor mediante el uso de descalificativos como 'rabioso' o 'salvaje' pone el acento en el carácter irreflexivo de su actitud y su conducta en el ataque discriminatorio. La construcción social del agresor (español) implica la atribución de un conjunto de características ajenas e incompatibles con el 'nosotros' (ecuatoriano). Así lo percibimos en el proceso de humanización (opuesto al del agresor) al que es sometida la víctima en la prensa ecuatoriana, donde se ponen de manifiesto su desprotección como menor y su origen extranjero.

La chica agredida es retratada de forma muy similar en los medios de los dos países, en los cuales se destaca su rol pasivo y paciente, su lugar de origen y su edad. De este modo, predominan las designaciones a su persona como 'la víctima' y 'la menor', siendo las caracterizaciones 'ecuatoriana' y 'de 16 años' las más frecuentes en ambos casos. No obstante, cabe señalar que en el periódico español $A B C$ la víctima es culpabilizada por desencadenar el ataque al haber mirado al agresor; acción que no comentan o desmienten otras fuentes en las que se cita a la chica negando que mirase al joven.

En los análisis de la representación y descripciones del testigo es donde encontramos mayor disparidad entre la prensa de los dos países. La prensa ecuatoriana le concede un papel que combina rasgos que son atribuidos tanto al agresor como a la víctima.Así, la indiferencia con la que actúa el testigo ante la agresión lo convierte, hasta cierto punto, en cómplice del agresor. En cambio, su pasividad y el desconcierto ante los hechos lo acercan a la representación socio-discursiva que recibe la agredida. La prensa española establece analogías entre el testigo y la chica, enfatizando el hecho de que sea inmigrante, así como su rol inactivo. Además, en la prensa ecuatoriana es el testigo quien representa en la escena la actitud más que habitual, a veces motivada por el miedo, de la falta de denuncia y protesta ante las prácticas excluyentes y discriminatorias que sacuden las sociedades modernas.

Una de las cuestiones que nos planteábamos al comienzo de este trabajo tenía por objeto responder cómo fue calificada la agresión en los textos de los dos países. En este sentido, la prensa es unánime al sostener que se trata de un ataque abusivo por parte de un mayor de edad hacia una menor el cual, para nosotros, implica una reprobable actitud xenófoba y racista en el agresor. Cabría preguntarse entonces cómo se hubieran narrado los hechos si dos personas (hombre y mujer) del mismo origen hubieran protagonizado el altercado del tren.

\section{CONCLUSIONES}

Con esta investigación hemos contribuido a los trabajos realizados en torno a las representaciones socio-discursivas $y$, más específicamente, a la construcción de los inmigrantes en la prensa. Con el propósito de analizar cómo se representaron los actores presentes en la agresión racista que tuvo lugar en un tren de cercanías de Barcelona agresor, víctima y testigo-, recopilamos un conjunto de textos periodísticos aparecidos en la prensa ecuatoriana (país de origen de la víctima) y española (país de origen del agresor), para confrontar los procedimientos lingüístico-discursivos mediante los cuales los medios escritos de ambos países reconstruyeron la escena a partir de una misma grabación que quedó registrada por una cámara de seguridad y que fue posteriormente difundida.

El análisis ha contado con los ECD (Estudios Críticos del Discurso) como marco de referencia. Concretamente, proponemos una conciliación de las orientaciones metodológicas de Ribas (1998, 200I, 2007, 2008) y KhosraviNik (20I0) para la descripción de los actores sociales. Partiendo de tres niveles de análisis (actores, caracterizaciones y acciones), realizamos una aproximación cuantitativa 
y cualitativa al estudio de las unidades lingüísticas (nominales, adjuntos y formas verbales) que intervienen en la 'construcción' de los tres actores implicados en la escena y que, en último término, 'perspectivizan' su representación socio-discursiva.

Como conclusión, comprobamos que existen diferencias significativas en el modo como se lleva a cabo la representación de cada uno de los actores. En Ecuador, se culpa directamente al agresor e indirectamente al testigo. Además, en la prensa ecuatoriana se conforma una representación sociodiscursiva en la que se intensifica o acentúa la imagen negativa de la sociedad receptora de la inmigración (la española) y, por el contrario, se atenúa la positiva. En los medios españoles, sin embargo, se propicia un proceso inverso: la imagen positiva del agresor se intensifica a través de una caracterización menos descalificativa que la que tiene lugar en la prensa ecuatoriana. De esta forma, el agresor se caracteriza en función de las variables edad y procedencia.
Por tanto, la procedencia y el origen de cada uno de los grupos de medios escritos que sometemos a análisis actúan como condicionantes claves para privilegiar la representación socio-discursiva positiva de los actores que pertenecen a cada nacionalidad. El hecho de que la perjudicada sea mujer e inmigrante no apunta hacia su representación negativa por parte del exogrupo. Por otro lado, y salvo en ocasiones aisladas $(A B C)$, tal como refleja la escena filmada y la posterior sentencia, la chica ecuatoriana es la víctima incuestionable de la agresión. Ahora bien, indirectamente, el tratamiento discursivo que recibe el agresor en la prensa española atenúa, como comprobamos, la magnitud de la agresión. En ese sentido, el privilegio del que goza el agresor en el endogrupo hace que el otro actor, sin dejar de ser víctima, lo sea en menor medida. Así pues, pensamos que este proceso de representación socio-discursiva responde a la condición de que la afectada fuera inmigrante (en concreto, ecuatoriana) y no española. 


\section{REFERENCIAS BIBLIOGRÁFICAS}

Abric, J. (1994). Metodología de recolección de las representaciones sociales. En J. Dacosta \& F. Flores (Eds.), Prácticas Sociales y Representaciones Sociales (pp. 53-75). México: Ediciones Coyoacán.

Aierbe, P. (2008). Representación de las mujeres trabajadoras inmigrantes en los medios de comunicación. En A. Bañón (Ed.), Comunicación, empleo y mujer inmigrante (pp. 7-20). Donosita-San Sebastián: Gakoa Liburuak.

Álvaro, J. \& Fernández, B. (2006). Representaciones sociales de la mujer. Athenea Digital: Revista de Pensamiento e Investigación Social, 9, 65-77.

Banchs, M. (1988). Cognición social y representación social. Revista de Psicología de El Salvador, VII(30), 36I-37I.

Belarbi, A. (2004). La dinámica de las representaciones sociales en una situación de inmigración. Revista CIDOB d'afers internacionals, 66-67, 8I-97.

Comas d'Argemir, D. (2008). Construyendo imaginarios, identidades, comunidades. El papel de los medios de comunicación. En M. Bullen \& C. Díez Mintegui (Eds.), Retos teóricos y nuevas prácticas (pp. 179-208). San Sebastián:Ankulegi.

Farr, R. \& Moscovici, S. (1984). Social representations. Londres: Cambridge University Press.

Gil de Montes, L., Elejabarrieta, F. \& Valencia J. (2004). Creencias y actitudes hacia la inmigración: Estereotipos, prejuicio y regulaciones normativas. Revista de Psicología Social, 19(3), 299318.

Hall, S. (1997). Representation: Cultural representations and signifying practices. Londres: Sage \& The Open University.

Jodelet, D. (1986). La representación social: Fenómenos, conceptos y teoría. En S. Moscovici (Ed.), Psicología social (pp. 469-494). Barcelona: Paidós.

Jodelet, D. (1989). Les représentations sociales: Un domaine en expansion. En D. Jodelet (Ed.), Les représentations sociales (Pp. 30-6I). París: PUF.

KhrosraviNik, M. (2010). Actor descriptions, action attributions, and argumentation: Towards a systematization of CDA analytical categories in the representation of social groups. Critical Discourse Studies, 7(I), 55-72.

Lario, M. (2008). La representación de la inmigración y de los inmigrantes en la prensa y en la radio. Estado de la cuestión. En A. Bañón \& J. Fornieles (Eds.), Manual sobre comunicación e inmigración (pp. 195-2 I4). Donosita-San Sebastián: Gakoa Liburuak.

Montero, G. (2006). Las representaciones sociales de los inmigrantes ecuatorianos en España sobre el proceso migratorio. Alternativas: Cuadernos de Trabajo Social, 14, 35-48.

Moral,J.\& Ortega,M.(2008).Diferencias de género en significados, actitudes y conductas asociados a la sexualidad en estudiantes universitarios. Estudios sobre las Culturas Contemporáneas, 28, 97-II9.

Ribas, M. (1998). Argumentación y representaciones sociales (la inmigración en el discurso parlamentario). Escritos, Revista del Centro de Ciencias del Lenguaje, I7-I8, 2 I 9-247.

Ribas, M. (200I). Discurs parlamentari i representacions socials: La representació de la "immigració" que emergeix de les preguntes d'una Comissió d'Estudi Parlamentària. Barcelona: Universitat Autònoma de Barcelona. 
Ribas, M. (2007). Construint i deconstruint identitats: Denominacions i designacions de la immigració. En M. Lorente, R. Estopà, J. Freixa, J. Martí \& C. Tebé (Eds.), Estudis de lingüística i de lingüística aplicada en honor de M. Teresa Cabré Castellví (pp. 40I-408). Barcelona: IULA, Documenta Universitaria.

Ribas, M. (2008). Discurso parlamentario e inmigración. En A. Bañón \& J. Fornieles (Eds.), Manual sobre comunicación e inmigración (pp. 453-466). Donosita-San Sebastián: Gakoa Liburuak.

van Dijk, T.A. (1997). Racismo y análisis crítico de los medios. Barcelona: Paidós.

van Dijk, T.A. (1998). Ideology. Londres: Sage.

van Dijk, T. A. (2000). On the analysis of parliamentary debates on immigration. En M. Reisigl \& R.Wodak (Eds.), The semiotics of racism. Approaches to critical discourse analysis (pp. 85103).Viena:Verlag.

van Dijk, T.A. (2007). Racismo y discurso en América Latina. Barcelona: Gedisa.

van Dijk, T.A. (2009). Critical Discourse Studies:A sociocognitive approach. En R.Wodak \& M. Meyer (Eds.), Methods of critical discourse analysis (pp. 62-85). Londres: Sage.

Van Leeuwen, T. (1996). The representation of social actors. En C. Caldas-Coulthard \& M. Coulthard (Eds.), Texts and practices. Readings in critical discourse analysis (pp. 32-70). Londres: Routledge.

Windisch, U. (1990). Le prêt-à-penser: Formes de la communication et de l'argumentation quotidiennes. Lausanne: L'Âge d'Homme. 


\section{ANEXO}

Texto de prensa ecuatoriana

Diario Hispano Ecuatoriano > Noticias

La denuncia ocupó las portadas de los medios

Indignación en Ecuador por agresión a joven emigrante en España

23-10-2007 - Hispanoecuatoriano (Quito)

Las imágenes de la brutal agresión que el español de $2 \mathrm{I}$ años, Sergi Xavier Echavía cometió contra una ecuatoriana de 16 años que viajaba en el tren de Barcelona provocó indignación generalizada en el Ecuador donde las imágenes se difundieron en todos los canales televisivos y fueron publicadas en las portadas de los principales periódicos. La queja se extendió también al trato que reciben los ecuatorianos en las oficinas de la embajada de España en este país.

La indignación de los presentadores de noticias de los canales de televisión fue evidente. Uno a uno fueron pasando los cuadros de la grabación que la cámara de seguridad del tren de Barcelona realizó el 7 de octubre pasado.

La joven ecuatoriana viajaba sola y en las imágenes solamente se ve otro pasajero sentado en un asiento cercano del tren cuando Sergio Xavier Echavía ingresa y se sienta atropelladamente, mientras habla por su teléfono celular.

Según se informó en la conversación el español, que ahora aduce haber estado "muy borracho" emite frases xenofóbicas. Se percata de la presencia de la joven emigrante a quien se le acerca insultante, luego le aplasta un seno y procede a golpearla una y otra vez en la cabeza.

Sorprendentemente cuando parece que terminaba el alevoso ataque, regresa y le lanza un puntapié en la cara.

Días después el agresor fue detenido en la región de Cataluña, pero según se informó localmente fue puesto en libertad bajo fianza.

Se espera que la Cancillería ecuatoriana presente su protesta diplomática por este hecho. Sin embargo los noticieros matinales de las cadenas Teleamazonas y Ecuavisa, dieron cuenta de permanentes maltratos que reciben los ecuatorianos que diariamente acuden a las oficinas de la embajada española en Ecuador para realizar sus trámites o solicitar un visado.
Texto de prensa española

Detienen a un joven que dio una paliza a una menor por ser ecuatoriana

ÁNGEL MARÍN. BARCELONA

23- | 0-2007 08:45:3 |

EI $A B C$

\section{Portada}

Sergio Javier M. M., de 21 años y vecino de Santa Coloma de Cervelló (Barcelona), fue detenido el pasado viernes por la Guardia Civil como presunto autor de la agresión de una menor de origen ecuatoriano en un tren de los Ferrocarriles de la Generalitat de Cataluña (FGC). La cámara de seguridad del vagón registró la brutal paliza que tiene tintes de ser un ataque racista.

En las imágenes del vídeo se aprecia cómo el joven entra en el tren manteniendo una conversación telefónica, y sin dejar de hablar por teléfono, insulta y golpea reiteradamente a la chica, de 16 años, que viajaba sola. Tras decirle al oído que se fuera a su país e insultarla ("zorra", "puta"...) al tiempo que le tocaba un pecho, el agresor hace amago de irse pero se da la vuelta $y$, sin mediar palabra, le propina un tremendo puntapié en la cara $y$, posteriormente, un puñetazo en la boca.

En el momento de la agresión, unos asientos más allá del que ocupaba la menor, había otro adolescente de origen suramericano en el vagón, que presenció los golpes e insultos a la chica sin ayudarla por miedo a ser también víctima de la ira del agresor.

\section{El detonante: La mirada}

Según explicó la joven ecuatoriana a la Guardia Civil, el individuo entró en el vagón hablando en voz alta por su móvil, con expresiones como «matar al moro», «inmigrantes de mierda» o «matar de un disparo», que le llamaron la atención. La mirada de la adolescente, que no intercambió ninguna palabra con su agresor, desencadenó, al parecer, la violencia con la que actuó Sergio, que tiene antecedentes penales por dos delitos de robo con violencia en 2004.

Los hechos denunciados por la joven sucedieron el pasado día 7 de octubre en el trayecto entre la estación barcelonesa de la Plaza de España y Martorell, 
poco antes de llegar al apeadero de la "Colonia Güell”, donde se bajó el agresor. Posteriormente, la adolescente llamó al I I 2, el teléfono de emergencias de la Generalitat, solicitando auxilio y dos agentes de la Guardia Civil atendieron a la menor, que se encontraba en estado de «shock», en la estación de Sants Vicenç dels Horts.

A partir de ese momento, el Área de investigación de la Guardia Civil de Barcelona inició las gestiones para localizar al presunto autor del ataque. Doce días más tarde, los agentes detuvieron a Sergio Javier M. M., que curiosamente llevaba la misma cazadora del día de la agresión a la menor, en la puerta de su domicilio en Santa Coloma de Cervelló.

El individuo, que actualmente está a disposición judicial, no reúne, al parecer, el perfil de ser miembro o militante de una organización xenófoba y racista, sino que todo indica que es un individuo que actúa con alta dosis, a veces gratuita, de violencia.

La asociación SOS Racismo condenó ayer la agresión racista que sufrió la menor de origen ecuatoriano. La ONG no tiene ninguna duda de que es un ataque racista porque "las palabras registradas dejan muy claro el contenido racista de los insultos que dirigía a la chica".

SOS Racismo considera que "manifestaciones de violencia racista como esta no pueden quedar impunes en un Estado de Derecho" y, por este motivo, ofrecen a la menor ecuatoriana sus servicios jurídicos para defender sus derechos "con el máximo de garantías" y trabajar para "conseguir una sentencia ejemplar". 